\title{
is Research Suare \\ Epidemiologic and Pathologic Study of Pancreatic Cancer in Hamadan, Iran (2008 to 2018)
}

\section{Elham Khanlarzadeh}

Hamadan University of Medical Sciences

Saman Nazari ( nsaman96@yahoo.com )

Hamadan University of Medical Sciences https://orcid.org/0000-0001-7928-0954

Mehdi Ghobakhlou

Hamadan University of Medical Sciences

\section{Hossein Ranjbar}

Hamadan University of Medical Sciences

\section{Sasan Nazari}

Hamadan University of Medical Sciences

\section{Research Article}

Keywords: Pancreatic cancer, Pathology, Epidemiology, Iran

Posted Date: June 9th, 2021

DOI: https://doi.org/10.21203/rs.3.rs-584615/v1

License: (9) (1) This work is licensed under a Creative Commons Attribution 4.0 International License. Read Full License 


\section{Abstract}

Purpose: Pancreatic cancer is the seventh leading cause of cancer death in cases. The study was conducted to determine the epidemiologic and pathologic of pancreatic cancer

Methods: A case series study was conducted retrospectively at Beheshti Hospital in Hamadan, Iran. A total of 409 cases that had been diagnosed with pancreatic cancer from 2008 to 2018 were reviewed. The variables included age, gender, occupation, pathological type, location involved, early symptoms, metastasis status, prognosis and treatments, was extracted from the files and recorded in checklist. Data were analyzed by using SPSS/20 software.

Results: Pancreatic cancer has been increasing trend in terms of time (2008-2018). Pancreatic cancer was most common age in the sixth decade of life and is more common in men than women. There was a significant relationship between aging and the incidence of pancreatic cancers $(P<0.05)$. Most of the subjects were urban (50.4\%). the frequency of smoking, alcohol and drugs were (34.5, 15.6 and $14.0 \%)$, respectively. Also, there was no statistically significant relationship between smoking, alcohol and drugs and pancreatic cancer $(P>0.05)$. The frequency of pancreatic cancers included Adenocarcinomas (66.7\%), Unknown (25.2\%), Mucinous Adenocarcinomas (4.2\%) and Carcinoma (3.9\%), respectively.

Conclusion: Pancreatic cancer has been increasing trend in terms of time. Pancreatic cancer was most common age in the sixth decade of life and is more common in men than women. The most common type of pancreatic cancer was Adenocarcinoma. Diagnosis usually occurs at higher stages. More preventive considerations were found to be beneficial among this population.

\section{Introduction}

Pancreatic cancer is the one of leading causes of cancer mortality in developed countries and one of the most lethal malignant neoplasms across the world. Most pancreatic cancers are adenocarcinoma, whereas other slower-growing pancreatic cancers include tumors and pancreatic neuroendocrine and exocrine cancers [1]. pancreatic cancer is the 12th most common malignancy and the 7th leading cause of cancer mortality [2]. According to GLOBOCAN database, in 2018, Due to weak prognosis of pancreatic cancer, from the number of patients $(n=459,000)$, and the number $(n=432,000)$ deaths occurred. Pancreatic cancer is the seventh leading cause of cancer death in cases. According to Human Development Index (HDI), pancreatic cancer is 3- 4 times more in higher HDI countries, and most prevalent in Europe, North America, and Australia/New Zealand [2]. with

the lowest incidence in Central Africa and Central Asia [3,4]. The mortality rate had a raising pattern by $25.4 \%$ to $39.9 \%$ worldwide from 2007 to 2017 deaths (7062 million versus 9.56 million). Also, the years of lost life (YLLs) in low SDI (socio demographic index) in the period between 1998 and 2017 increased from 38.6 to 55.9 per $100,000[4]$.

In Iran, pancreatic cancer resembling to that of western countries as it affects men more than women $[5,6]$, and also mortality rate in males is more than females [7]. The frequency of pancreatic cancer is more in the eighth decade of life [8]. The results of the studies indicate an elevation in the incidence and mortality of pancreatic cancer in different parts of Iran [8,9]. The predisposing factors for pancreatic cancer including, age increasing, obesity, diabetes mellitus, genetic, family history of cancer, smoking, drinking alcohol $[10,11]$, chronic 
pancreatitis [12], decrease physical activity [13], and poor vegetables consumption [14, 15]. Shakeri et al., reported that in the years 2011 to 2015, after adjusting for the variables, narcotic and alcohol significantly increases the risk of pancreatic cancer, but no correlation was found between using cigarette and pancreatic cancer [16]. The purpose of this survey was to evaluate the epidemiologic and pathologic of pancreatic cancer from 2008 to 2018 in Hamadan, Iran.

\section{Materials \& Methods}

A case series study was conducted retrospectively at Beheshti Hospital in Hamadan city, Iran. A total of 409 cases of patients who had been diagnosed with pancreatic cancer from 2008 to 2016 and had a medical record were reviewed. The required information including age, gender, occupation, location, pathological type of cancer, location involved, the primary sign of presentation, prognosis and treatments, were extracted from the files and the checklist was completed. File deficiencies have been followed up by telephone.

Diagnosis of different types of pancreatic cancer was based on International Statistical Classification of Diseases and Related Health Problems $10^{\text {th }}$ Revision (ICD-10). C25.0- C25.9 was considered as "malignant neoplasm of pancreas" in the current study. ICD is the foundation for the identification of health trends and statistics globally, and the international standard for reporting diseases and health conditions. It is the diagnostic classification standard for all clinical and research purposes [17]. Data processing and statistical analysis were performed by using SPSS/20 software and chi-square test. P value $<0.05$ was regarded as significant.

\section{Results}

In this case-series study, 409 patients who referred to Beheshti Hospital in Hamadan from 2008 to 2018 following the diagnosis of pancreatic cancers were included in the study. The frequency of pancreatic cancers included Adenocarcinomas 273 (66.7\%), Unknown 103 (25.2\%), Mucinous Adenocarcinomas 17 (4.2\%) and Carcinoma 16 (3.9\%), respectively.

Based on the results of Chi-square test, the highest number of subjects was in the age group between 60-69 year, and lowest frequency was in the age group of $\geq 49$ year. There was a significant relationship between aging and the incidence of pancreatic cancers $(P<0.05)$.

Pancreatic cancers were more common in men $(60.1 \%)$. There is also no significant relationship between gender and the frequency of pancreatic cancers $(P=0.99)\left(X^{2}-\right.$ Test $)$.

The occupations of the majority of the subjects were unemployed (31.3\%). Also, there is no significant relationship between job and the incidence of pancreatic cancers $(P=0.76)$. Most of the subjects were urban $(50.4 \%)$ and also there was no significant relationship between residence and pancreatic cancers $(P=0.75)(X 2$ -Test) (Table 1). 
Table 1

Baseline characteristics of participants by units of research

\begin{tabular}{|c|c|c|c|c|c|c|}
\hline \multirow[t]{2}{*}{ Characteristics } & \multicolumn{4}{|c|}{$\begin{array}{l}\text { Type of Pancreatic Cancer No. (\%) } \\
(n=409)\end{array}$} & \multirow[t]{2}{*}{ Total } & \multirow[t]{2}{*}{$\begin{array}{l}\text { P- } \\
\text { value* }\end{array}$} \\
\hline & $\begin{array}{l}\text { Adenocarcinoma } \\
\text { (M8140) }\end{array}$ & $\begin{array}{l}\text { Unknown } \\
\text { (M8000) }\end{array}$ & $\begin{array}{l}\text { carcinoma } \\
\text { (M8010) }\end{array}$ & $\begin{array}{l}\text { Mucinous } \\
\text { Adenocarcinoma } \\
\text { (M) }\end{array}$ & & \\
\hline \multicolumn{6}{|l|}{ Age (Yr.) } & \multirow[t]{6}{*}{0.02} \\
\hline$=<49$ & $9(8.7)$ & $25(9.2)$ & $4(25.0)$ & $4(23.5)$ & 42(10.3) & \\
\hline $50-59$ & $27(26.2)$ & $45(16.5)$ & $4(25.0)$ & $4(23.5)$ & $80(19.6)$ & \\
\hline $60-69$ & $35(34.0)$ & $80(29.3)$ & $3(18.8)$ & $3(17.6)$ & 121(29.6) & \\
\hline $70-79$ & 24(23.3) & $67(24.5)$ & $3(18.8)$ & $4(23.5)$ & $98(24.0)$ & \\
\hline$>=80$ & $8(7.8)$ & $56(20.5)$ & $2(12.5)$ & $2(11.8)$ & $68(16.6)$ & \\
\hline \multicolumn{6}{|l|}{ Gender } & \multirow[t]{3}{*}{0.99} \\
\hline Male & $63(61.2)$ & 163(59.7) & $10(62.5)$ & $10(58.8)$ & $246(60.1)$ & \\
\hline Female & 40(38.8) & $110(40.3)$ & $6(37.5)$ & $7(23.5)$ & 163(39.9) & \\
\hline \multicolumn{6}{|l|}{ Job } & \multirow[t]{5}{*}{0.76} \\
\hline Employed & $13(12.6)$ & $56(20.5)$ & $3(18.8)$ & $4(23.5)$ & 42(10.3) & \\
\hline Un employed & $36(34.9)$ & $81(29.6)$ & $6(37.5)$ & $5(29.4)$ & 128(31.3) & \\
\hline Farmer & $26(25.2)$ & $70(25.6)$ & $3(18.8)$ & $6(35.3)$ & $105(25.7)$ & \\
\hline Worker & $28(27.2)$ & $66(24.2)$ & $4(25.0)$ & $2(11.8)$ & 100(24.4) & \\
\hline \multicolumn{6}{|l|}{ Residence } & \multirow[t]{4}{*}{0.75} \\
\hline Urban & $54(52.4)$ & 133(48.7) & $9(56.2)$ & $10(58.8)$ & $206(50.4)$ & \\
\hline Rural & $49(47.6)$ & 140(51.3) & $7(43.8)$ & $7(41.2)$ & 203(49.6) & \\
\hline Total & 103(100.0) & 273(100.0) & 16(100.0) & 17(100.0) & 409(100.0) & \\
\hline
\end{tabular}


Table 2

Frequency of Smoking, alcohol substance abuse among the subjects $((n=$ 409))

\begin{tabular}{|c|c|c|c|c|}
\hline & \multicolumn{2}{|c|}{$\begin{array}{l}\text { Pancreatic cancer } \\
\text { No. (\%) }\end{array}$} & \multirow[t]{2}{*}{ Total } & \multirow[t]{2}{*}{ P-value* } \\
\hline & Yes & No & & \\
\hline Smoking & 141(34.5) & 268(64.5) & 409 (100.0) & 0.05 \\
\hline Alcohol & $64(15.6)$ & $345(84.4)$ & $409(100.0)$ & 0.06 \\
\hline Substance abuse & $57(14.0)$ & $352(86.0)$ & 409 (100.0) & 0.05 \\
\hline
\end{tabular}

Based on the results of Chi-square test, the table above showed the frequency of smoking (34.5\%), alcohol (15.6\%) and drugs (14.0\%) in the subjects. Also, there was no statistically significant relationship between smoking, alcohol and drugs and pancreatic cancer $(P>0.05)$ (Table 2).

Pancreatic cancer has been increasing trend in the frequency of patients in terms of time, and we see an increase in the number of patients from 14 in 2008 to 41 in 2018. The frequency distribution of pancreatic cancer patients by year (2008-2018) has been shown. The highest number of cases in 2017 was 62 and the lowest cases in 2008 were 14 cases (Fig. 1).

\section{Discussion}

In the present study, overall, pancreatic cancer has been increasing trend in the frequency of patients in terms of time, and we see an increase in the number of patients from 14 in 2008 to 41 in 2018. Pancreatic cancers were more common in men than women. The highest number of subjects was in the age group between 60-69 year, and the lowest frequency was in the age group of $\geq 49$ year. There was a significant relationship between aging and the frequency of pancreatic cancers. Most of the subjects were married and urban. The occupations of the majority of the subjects were unemployed. The majority of pancreatic cancers were Adenocarcinoma (66.7\%). there was no statistically significant relationship between smoking, alcohol and drugs and pancreatic cancer.

Siri and Salehinyia found that the incidence and mortality rate of pancreatic cancer increased in Iran, the average age of subjects was 63 years. The incidence rate was 1.18 and 0.84 in men and women per 100,000 healthy people, respectively. Smoking, aging and lifestyle are the most important factors in cancer. Due to the lack of clear symptoms and markers in the diagnosis of the disease at the early stages, these patients are usually diagnosed at the advanced stages and have a low survival rate. The incidence increased with age, and the survival rate was relatively low [11]. This survey is consistent with the findings of present study.

Another study concluded that men are more likely to come down with this disease than women. The prevalence of this cancer was 9.8 in total, which were 11.9 in the male population and 5.7 in the female population per 100,000 of people. The average age of the subjects was 65.7 years. The minimum and the maximum age of patients were 12 and 94 years, respectively. The prevalence was $58.9 \%$ higher in men than women and $82 \%$ of the participants were between 40 and 80 years [18]. In the present study, the prevalence was higher in men and the average age of the subjects was 66.3 years, which is consistent with the findings of this study. 
Rawla et al. In a review study in 2019 inferred that the most common type of pancreatic cancer is adenocarcinoma, which accounts for about $85 \%$ of cases and has a lower prognosis than other types of pancreatic cancers [19]. Based on the pathological evaluations, most of cases were adenocarcinoma, which is consistent with the findings of this study.

The incidence of pancreatic cancer is more in the eighth decade of life [8]. Smoking is the most common known risk factor, and is the cause of $20-25 \%$ of all pancreatic tumors. Alcohol does not seem to be a risk factor, unless it leads to chronic

pancreatitis, which is a probable risk factor [20]. Increased smoking in developing countries, quick diagnosis and rising life are all likely to increase the global burden of pancreatic cancer in the future. In an analysis of data from 48 countries, they found rising incidence and mortality trends in pancreatic cancer-especially among people over 50 years of age [21]. The incidence and mortality rate of pancreatic cancer is steadily increasing with age. Actually, men are more likely to develop this carcinoma than women. Smoking, aging, and lifestyle changes are the most important risk factors for pancreatic cancer in Iran. Due to the lack of initial symptoms or a specific marker for early diagnosis of pancreatic cancer, this cancer is detected lately and therefore low survival rate is observed [11]. Zahir et al. [13] conducted a study in Yazd in 2001-2011 and concluded that the incidence of pancreatic cancer increased from 0.55 in 2001 to 1.68 per 100,000 in 2011. The standardized incidence rate for age in 2001 and 2011 was 0.75 and 2.68, respectively. There was a significant rise in the incidence of cancer in 11 years of study in Yazd [8]. In the present study, pancreatic cancer had a rising pattern during a ten years period (2008-2018).

The etiology of pancreatic cancer is still insufficiently known, although some risk factors have been identified, such as Substance abuse, positive family history and genetics, dietary factors, and physical inactivity. There are no current screening recommendations for pancreatic cancer, so primary prevention is of utmost importance.

\section{Conclusion}

Pancreatic cancer has been increasing trend in terms of time. Pancreatic cancer was most common age in the sixth decade of life and is more common in men than women. The most common type of pancreatic cancer was Adenocarcinoma. Diagnosis usually occurs at higher stages. More preventive considerations are found to be beneficial among this population.

\section{Declarations}

\section{Funding}

This study was supported by Deputy of Research \& Health in Hamadan University of Medical Sciences, Hamadan, Iran.

\section{Availability of data and material}

All the data was collected from original patient's files.

\section{Code availability}


Not applicable' for this section.

\section{Compliance with Ethical Standards}

This article does not contain any studies with human participants or animals performed by any of the authors.

\section{Conflict-of-interest statement}

No potential conflicts of interest.

\section{Ethics approval}

This research is based on the Medical Doctoral Thesis approved by Research Deputy of Hamadan University of Medical Sciences with Project No. 9809126662. The ID Code of Ethics Committee was IR.UMSHA.REC.1398.660.

\section{Consent to participate}

This article does not contain any studies with human participants or animals performed by any of the authors.

\section{Consent for publication}

There is a covering letter for this manuscript.

\section{Author contributions}

Saman Nazari conceived the idea, planned the study and drafted the manuscript. All authors helped acquisition of data, did statistical analysis, editing and final approval of manuscript. All authors contributed significantly to the submitted manuscript.

\section{Acknowledgements}

This research is based on the Medical Doctoral Thesis approved by Research Deputy of Hamadan University of Medical Sciences with Project No. 9809126662. The ID Code of Ethics Committee was IR.UMSHA.REC.1398.660. This study was supported by Deputy of Research \& Health in Hamadan University of Medical Sciences, Hamadan, Iran.

\section{References}

1. Yadav $D$ and Lowenfels $A B$. The epidemiology of pancreatitis and pancreatic cancer. Gastroenterology. 2013; 144(6): 1252-1261.

2. Bray F, Ferlay J, Soerjomataram I, Siegel RL, Torre LA, Jemal A. Global cancer statistics 2018: GLOBOCAN estimates of incidence and mortality worldwide for 36 cancers in 185 countries. CA: a cancer journal for clinicians. 2018; 68(6): 394-424.

3. Ilic M. and Ilic I. Epidemiology of pancreatic cancer. World journal of gastroenterology. 2016; 22(44): 9694.

4. Roth GA, Abate D, Abate KH, Abay SM, Abbafati C, Abbasi N, et al. Global, regional, and national age-sex-specific mortality for 282 causes of death in 195 countries and 
territories, 1980-2017: a systematic analysis for the Global Burden of Disease Study 2017. The Lancet. 2018; 392(10159): 1736-1788.

5. Ahmadloo N, Bidouei F, Omidvari S, Ansari M, Mosalaei A, Mohammadianpanah M. Pancreatic cancer in southern Iran. 2010: 624-630.

6. Hadizadeh M, Padashi M, Mohammad Alizadeh A, Zali MR. Clinical, laboratory biomarkers and imaging findings of pancreatic adenocarcinoma in Iran. Asian Pacific Journal of Cancer Prevention. 2014; 15(10): 4349-4352.

7. Pourhoseingholi MA, Fazeli Z, Ashtari S, Bavand-Pour FSF. Mortality trends of gastrointestinal cancers in Iranian population. Gastroenterology and hepatology from bed to bench, 2013. 6(Suppl 1): S52-57.

8. Zahir ST, Arjmand A, Kargar S, Neishaboury M. Incidence and trends of malignant and benign pancreatic lesions in Yazd, Iran between 2001 and 2011. Asian Pacific Journal of Cancer Prevention, 2013; 14(4): 2631-2635.

9. Salehi F, Ahmadi A, Ahmadi Soodejani SS, Shahini Shams

Abadi M. The changing trend of mortality caused by gastrointestinal cancers in Iran during the years 20062010. Arquivos de gastroenterologia. 2018; 55(3): 237-241.

10. Pandol, S., et al., Epidemiology, risk factors, and the promotion of pancreatic cancer: role of the stellate cell. Journal of gastroenterology and hepatology. 2012; 27: 127-134.

11. Siri FH, Salehiniya H. Pancreatic cancer in Iran: An epidemiological review. Journal of gastrointestinal cancer. 2020; 51(2): 418-424.

12. Bosetti C, Bravi F, Turati F, Edefonti V, Polesel J, Decarli A, et al. Nutrient-based dietary patterns and pancreatic cancer risk. Annals of epidemiology. 2013; 23(3): 124-128.

13. Zhang Q, Zeng L, Chen Y, Lian G, Qian C, Chen S, et al. Pancreatic cancer epidemiology, detection, and management. Gastroenterol Res Pract. 2016;2016:8962321. https://doi.org/10.1155/2016/8962321.

14. Ghorbani Z, Hekmatdoost A, Poustchi H, Pourshams A, Malekshah AF, Sharafkhah M, et al. Higher intake of dietary fiber, but not fruits or vegetables is associated with lower risk of pancreatic cancer: a large prospective study. Govaresh, 2017; 22(1): 17-27.

15. Shobeiri F. Afshari KD.Nazari S. Nazari S. Farhadian M. Effect of nutritional program on nutritional behavior in pregnant women at Hamadan, Iran. Journal of Postgraduate Medical Institute . 2018; 32(4): 368-371.

16. Shakeri R. Kamangar F, Mohamadnejad M, Tabrizi R, Zamani F, Mohamadkhani A, et al. Opium use, cigarette smoking, and alcohol consumption in relation to pancreatic cancer. Medicine, 2016; 95(28): 3922. https://icd.who.int/browse10/2019/en.

17. Tolou-Ghamari Z. Pancreatic cancer: Demographics and prevalence. Clinical Cancer Investigation Journal. 2020; 9(4): 155.

18. Rawla P, Sunkara T, Gaduputi V. Epidemiology of pancreatic cancer: global trends, etiology and risk factors. World Journal of Oncology. 2019; 10(1): 10.

19. Raimondi S, Lowenfels AB, Morselli-Labate AM, Maisonneuve P, Pezzilli R. Pancreatic cancer in chronic pancreatitis; aetiology, incidence, and early detection. Best practice \& research Clinical gastroenterology. 2010; 24(3): 349-358.

20. Huang J, Lok V, Ngai CH, Zhang L, Yuan J, Lao XQ, et al. Worldwide burden of, risk factors for, and trends in pancreatic cancer. Gastroenterology.2021; 160(3): 744-754. 
Figures

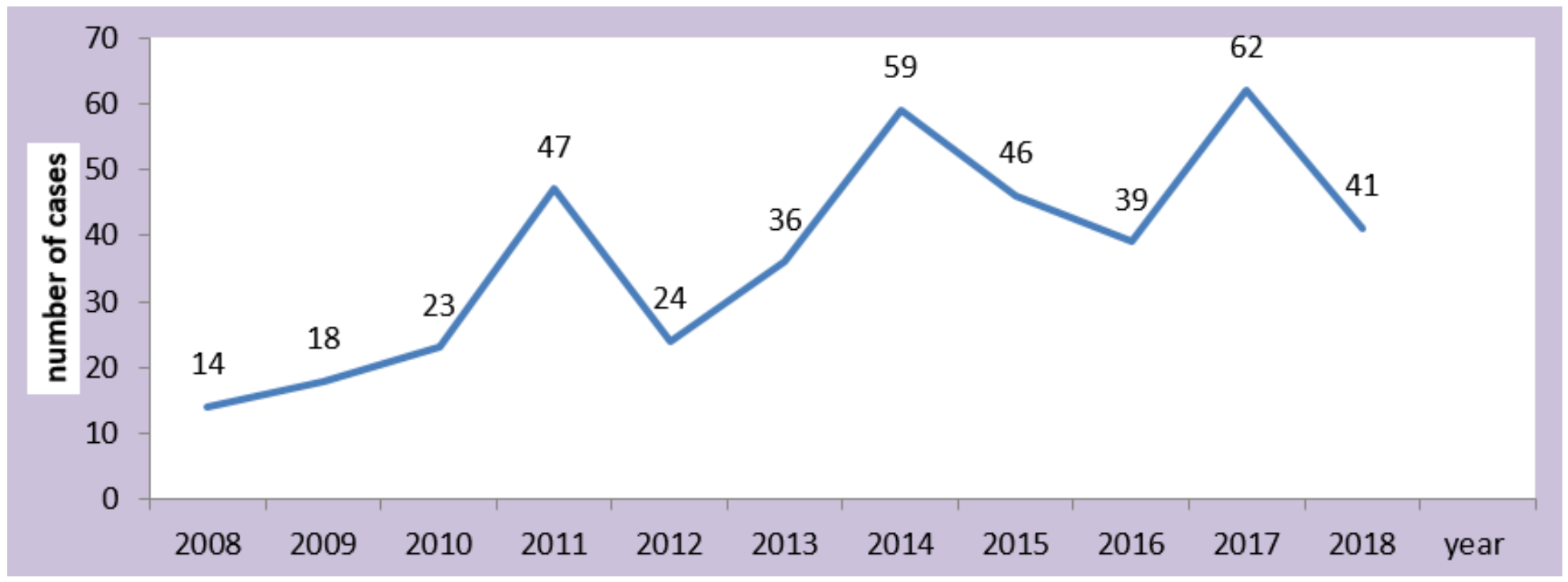

Figure 1

Frequency of pancreatic cancer cases from 2008 to 2018 